\title{
Predictive Control of a Three-Phase UPS Inverter Using Two Steps Prediction Horizon
}

\author{
Patricio Cortes and Jose Rodriguez \\ Departamento de Electronica \\ Universidad Tecnica Federico Santa Maria \\ Avenida España 1680, Valparaiso, Chile \\ Email: patricio.cortes@usm.cl
}

\author{
Sergio Vazquez and Leopoldo G. Franquelo \\ Electronics Engineering Department \\ University of Seville \\ Seville, Spain \\ Email:svazquez@zipi.us.es
}

\begin{abstract}
A Model Predictive Control scheme is used for voltage control in a three-phase inverter with output LC filter. The controller uses a model of the system to calculate predictions of the future value of the system variables for a given voltage vector sequence. A cost function considering the voltage errors is defined and the voltage vectors that minimize it is selected and applied in the converter.

The effect of considering different number of prediction steps is studied in this work in terms of THD. Simulation results for one and two prediction steps are presented and compared.
\end{abstract}

\section{INTRODUCTION}

The inclusion of an output LC filter allows the inverter to provide high quality sinusoidal voltages, but it makes more difficult the controller design and controller parameters adjustment. Moreover, for uninterruptible power supplies (UPS) applications, it is important to achieve a good output voltage regulation with any kind of load, being very important that the functionality of the system does not deteriorate under nonlinear loads, such as diode rectifiers.

Several control schemes have been proposed for this converter, including deadbeat control [1], [2], [3], multiloop feedback control [4], [5], [6], adaptive control based on bank resonant filters [7], [8], repetitive-based controllers [9], [10]. Some tuning strategies have been presented including $\mathrm{H}$ infinity control design [11]. In most of these schemes the output voltage and one of two currents are used in a cascaded control structure considering outer and inner control loops, with linear or nonlinear controllers, and an external modulator to generate the firing pulses for the power semiconductors.

Predictive control appears as an attractive alternative for the control of power converters due to its fast dynamic response [12]. Several control algorithms have been presented under the name of predictive control, as presented in [13]. Among these control schemes, Model Predictive Control (MPC) has demonstrated to be a very interesting alternative for the control of power converters and drives. It uses a model of the system to predict the behavior of the variables until a certain horizon of time, then the optimal future actions are selected by minimization of a cost function [15], [16], [17]. MPC is a very flexible control scheme that allows easy inclusion of system constraints and nonlinearities in the design stage of the controller. In MPC, different formulations of the cost function

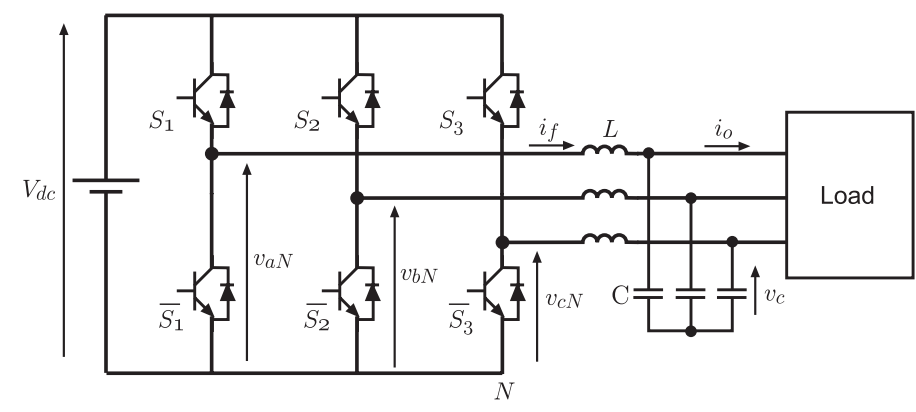

Fig. 1. Three-phase inverter with output LC filter.

are possible, considering different norms and including several variables and weighting factors [12]. The inputs of the system can be considered continuous, by using a modulator to apply the optimal voltages, as presented in [14], [21]. In order to simplify the implementation of MPC, the converter can be modelled as a system with a finite number of switching states, as presented for the current control in a matrix converter in [22], [23], a three-phase inverter in [24], [25], an active front end rectifier [26], a multilevel inverter [27] and a flying capacitor converter [28]. This way, all possible switching states can be evaluated online, then the one that minimizes the cost function is selected. All these control schemes control schemes consider only one time step horizon. However, it is also possible to consider different prediction horizons, as shown in [20], improving the behavior of the system but increasing the complexity of the system and the computational cost.

This work studies the benefit of considering two steps prediction in the control of an UPS system. The improvement is measured in terms of THD of the output voltage. Results are compared with the same system operating with only one step prediction, considering resistive and nonlinear loads. A method of reduction of the number of calculations without affecting the performance is proposed.

\section{SySTEM MODEL}

The equation of the filter inductance expressed in vectorial form is:

$$
L \frac{d \mathbf{i}_{f}}{d t}=\mathbf{v}_{i}-\mathbf{v}_{c}
$$

where $L$ is the filter inductance. 




Fig. 2. Voltage vectors generated by the inverter.

The dynamic behavior of the output voltage can be expressed by the following equation:

$$
C \frac{d \mathbf{v}_{c}}{d t}=\mathbf{i}_{f}-\mathbf{i}_{o}
$$

where $C$ is the filter capacitance.

These equations can be rewritten as a state space system as

$$
\frac{d \mathbf{x}}{d t}=A \mathbf{x}+B \mathbf{v}_{i}+B_{d} \mathbf{i}_{o}
$$

where

$$
\begin{gathered}
\mathbf{x}=\left[\begin{array}{c}
\mathbf{i}_{f} \\
\mathbf{v}_{c}
\end{array}\right] \\
\mathbf{A}=\left[\begin{array}{cc}
0 & -1 / L \\
1 / C & 0
\end{array}\right] \\
\mathbf{B}=\left[\begin{array}{c}
1 / L \\
0
\end{array}\right], \mathbf{B}_{d}=\left[\begin{array}{c}
0 \\
-1 / C
\end{array}\right]
\end{gathered}
$$

Variables $\mathbf{i}_{f}$ and $\mathbf{v}_{c}$ are measured, and $\mathbf{i}_{o}$ is considered a disturbance that can be measured or estimated using an observer, as presented in [29]. In this work, the value of $V_{d c}$ is assumed fixed and known.

The output of the system is the output voltage $\mathbf{v}_{c}$, and written as a state equation:

$$
\mathbf{v}_{c}=\left[\begin{array}{ll}
0 & 1
\end{array}\right] \mathbf{x}
$$

The inverter voltage $\mathbf{v}_{i}$ is the input of the system and belongs to a finite set of 7 voltage vectors defined by the possible switching states of the inverter, as shown in Fig. 2.

\section{A. Discrete-time model of the filter}

A discrete-time model of the filter is obtained from (3) for a sampling time $T_{s}$, and is expressed as:

$$
\mathbf{x}(k+1)=\mathbf{A}_{q} \mathbf{x}(k)+\mathbf{B}_{q} \mathbf{v}_{i}(k)+\mathbf{B}_{d q} \mathbf{i}_{o}(k)
$$

where

$$
\begin{aligned}
\mathbf{A}_{q} & =e^{\mathbf{A} T_{s}} \\
\mathbf{B}_{q} & =\int_{0}^{T_{s}} e^{\mathbf{A} \tau} \mathbf{B} d \tau \\
\mathbf{B}_{d q} & =\int_{0}^{T_{s}} e^{\mathbf{A} \tau} \mathbf{B}_{\mathbf{d}} d \tau
\end{aligned}
$$

This model is used to calculate predictions of the output voltage $\mathbf{v}_{c}$ for a given input voltage vector $\mathbf{v}_{i}$. The selection of the optimal voltage vector to be applied in the converter is made using the predictive control scheme presented in the next section.

\section{MODEL PREDICTIVE CONTROL OF AN UPS}

A block diagram of the model predictive control scheme used in this work is presented in Fig. 3. The discrete-time model of the system is used to calculate predictions of the output voltage until time $k+N$ for a given sequence of inverter voltage vectors and measurements at time $k$. A cost function to be minimized evaluates the error between the output voltage predictions and the reference voltage. The sequence of votage vectors that minimize this function is selected and the first element is applied. This algorithm is repeated each sampling time.

\section{A. Cost function}

The cost function $g_{N}$ is defined as the sum of all square errors between the reference and predicted voltage vectors from time $k+1$ until time $k+N$.

$g_{N}=\sum_{n=1}^{N}\left(v_{c \alpha}^{*}-v_{c \alpha}^{p}(k+n)\right)^{2}+\left(v_{c \beta}^{*}-v_{c \beta}^{p}(k+n)\right)^{2}+h_{l i m}$,

where $v_{c \alpha}^{*}$ and $v_{c \beta}^{*}$ are the real and imaginary parts of the reference voltage vector $\mathbf{v}_{c}^{*}$, and $v_{c \alpha}^{p}(k+n)$ and $v_{c \beta}^{p}(k+n)$ are the real and imaginary parts of the predicted voltage vector $\mathbf{v}_{c}^{p}(k+n)$, calculated using (8) for a given inverter voltage vector sequence $\left[\mathbf{v}_{i}(k), \cdots, \mathbf{v}_{i}(k+N-1)\right]$. An additional term $h_{\text {lim }}$ is included in the cost function in order to limit the inverter output currents, and is defined as:

$$
h_{\text {lim }}= \begin{cases}0 & \text { if }\left|\mathbf{i}_{f}(k+1)\right| \leq i_{\max } \\ \infty & \text { if }\left|\mathbf{i}_{f}(k+1)\right|>i_{\max }\end{cases}
$$

In this way, if the magnitude of the predicted filter current $\mathbf{i}_{f}(k+1)$ is larger than the allowed maximum value $i_{\max }$ for a given inverter voltage vector, the value of the cost function will be $\infty$, and this voltage vector will not be selected. In the other hand, if the predicted filter current is lower than the maximum value, the cost function considers only the output voltage errors.

In this work, the voltage reference is kept constant until time $k+N$ and equal to $\mathbf{v}_{c}^{*}(k)$. However, it is possible the use of extrapolation methods in order to calculate the future values of the reference voltage. 




Fig. 3. Model predictive control of an UPS.



a)



b)

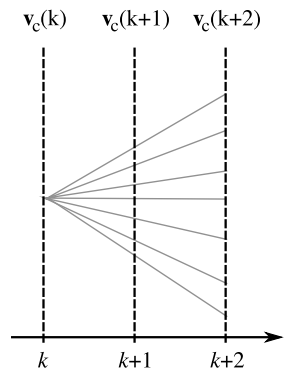

c)

Fig. 4. Prediction of the output voltages considering different input sequences. a) One step prediction. b) Two steps prediction considering different voltages during each sampling period. c) Two steps prediction considering the same voltages applied during two sampling periods.

\section{B. Selection of the set of voltage vector sequences}

When only one step prediction is considered, the effect of applying a voltage vector during one sampling period is evaluated. In this case only seven voltage vectors are considered. When two steps are considered for prediction, one voltage vector is applied during the first sampling period and another voltage vector is applied during the second sampling period. In this case, 49 sequences of two voltage vectors are possible. For $N$ steps, a total of $7^{N}$ possible sequences must be evaluated. This leads to a very high number of calculations, which can make very difficult the experimental implementation of the algorithm.

In order to reduce the number of calculations, it is possible to evaluate the application of the same voltage vector during $N$ steps, instead of different vectors. This approach simplifies the algorithm and, as will be shown in the next section, presents a similar performance than evaluating different vectors for the same number of steps. The different approaches considered in this work are represented in Fig. 4 for one and two steps.

\section{RESUlts}

The performance of the proposed model predictive controller is tested by simulation using PSCAD. The system parameters are listed in Table I. Behavior of the system is evaluated for one and two prediction steps. Resistive loads and nonlinear loads are considered.

\section{A. One step prediction}

The use of MPC with only one step prediction is similar to the one presented in [29]. It considers the following cost function

$$
g_{1}=\left(v_{c \alpha}^{*}-v_{c \alpha}^{p}(k+1)\right)^{2}+\left(v_{c \beta}^{*}-v_{c \beta}^{p}(k+1)\right)^{2}+h_{l i m},
$$

which is evaluated for each one of the seven voltage vectors generated by the inverter.

The output voltage and current, and the filter current obtained using one step prediction are shown in Fig. 5 for resistive load.

\section{B. Prediction horizon larger than 1}

The behavior of the system using MPC with two steps prediction is shown in Fig. 6 for resistive load. The cost function for these results is

$$
\begin{aligned}
g_{2}= & \left(v_{c \alpha}^{*}-v_{c \alpha}^{p}(k+1)\right)^{2}+\left(v_{c \beta}^{*}-v_{c \beta}^{p}(k+1)\right)^{2} \\
& +\left(v_{c \alpha}^{*}-v_{c \alpha}^{p}(k+2)\right)^{2}+\left(v_{c \beta}^{*}-v_{c \beta}^{p}(k+2)\right)^{2}+h_{\text {lim }}
\end{aligned}
$$

Here, two cases are considered: using different vectors in each sampling period (Fig. 6.(a)) and using the same vector during two sampling periods (Fig. 6.(b)). It can be observed that in both cases the performance is very similar and considerably better that the case of one step prediction. This improvement can be noticed in the lower THD and in less ripple in the output voltage.

Considering that the behavior of the system using two steps is almost the same with the evaluation of two different vectors and the evaluation of the same vector during two sampling period, and the higher amount of calculations required by the first case, the second case is selected for extension to three steps prediction. It was observed that the THD is increased when a three steps prediction is considered. This is due to

TABLE I

PARAMETERS OF THE SYSTEM.

\begin{tabular}{ll} 
Parameter & Value \\
\hline DC link voltage $V_{d c}$ & $520[\mathrm{~V}]$ \\
Filter inductance $L$ & $2.4[\mathrm{mH}]$ \\
Filter capacitor $C$ & $20[\mu \mathrm{F}]$ \\
Sampling time $T_{s}$ & $50[\mu s]$
\end{tabular}



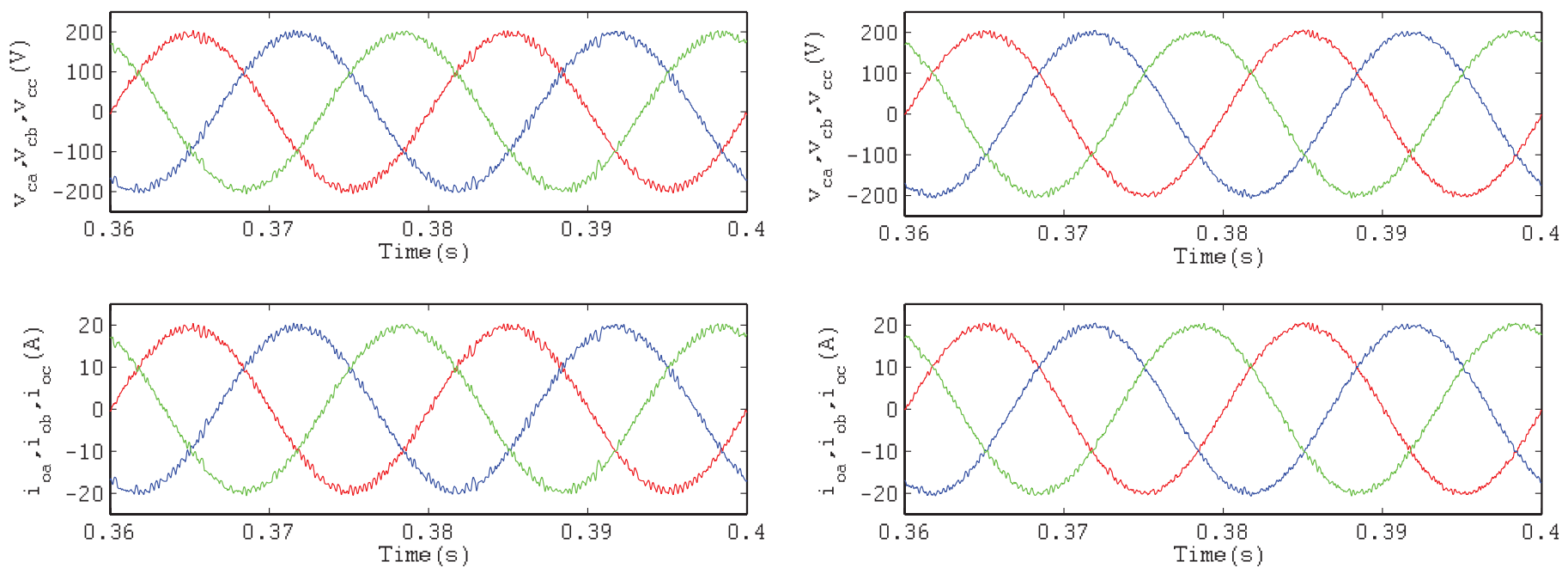

Fig. 5. One step prediction with resistive load. THD $=2.15 \%$.

the assumptions and approximations considered for the model, which are not valid for such long prediction horizons.

Performance of the proposed controller for a nonlinear load composed by a three-phase resistor and three singlephase diode bridge rectifiers, as the one shown in Fig. 7, connected between the phases of the output filter. Results are shown in Fig. 8 and Fig. 9, for one and two step prediction, respectively. It can be observed that the improvement with two steps prediction is even more noticeable than with resistive loads.

A summary of the THD value obtained using different number of prediction steps is shown in Table II.

TABLE II

COMPARISON OF THD VALUES FOR DIFFERENT NUMBER OF PREDICTION STEPS.

\begin{tabular}{ll} 
Number of prediction steps & THD \% \\
\hline Resistive load & \\
1 step & 2.15 \\
2 steps (same vector during $2 T_{s}$ ) & 1.54 \\
2 steps (different vectors) & 1.56 \\
Nonlinear load & \\
1 step & 2.85 \\
2 steps (same vector during $2 T_{s}$ ) & 2.17 \\
2 steps (different vectors) & 2.19
\end{tabular}

\section{Conclusions}

A model predictive control for an UPS system considering two steps prediction is presented. It can be observed that the behavior of the system improves when a higher number of prediction steps is considered. However, when the number of prediction steps is increased, the number of calculations increases exponentially.

This paper shows that the problem of high number of calculations can be simplified by considering the application of the same voltage vector for several sampling periods. However, there is no improvement for more than two prediction steps, because the assumptions and approximations considered for
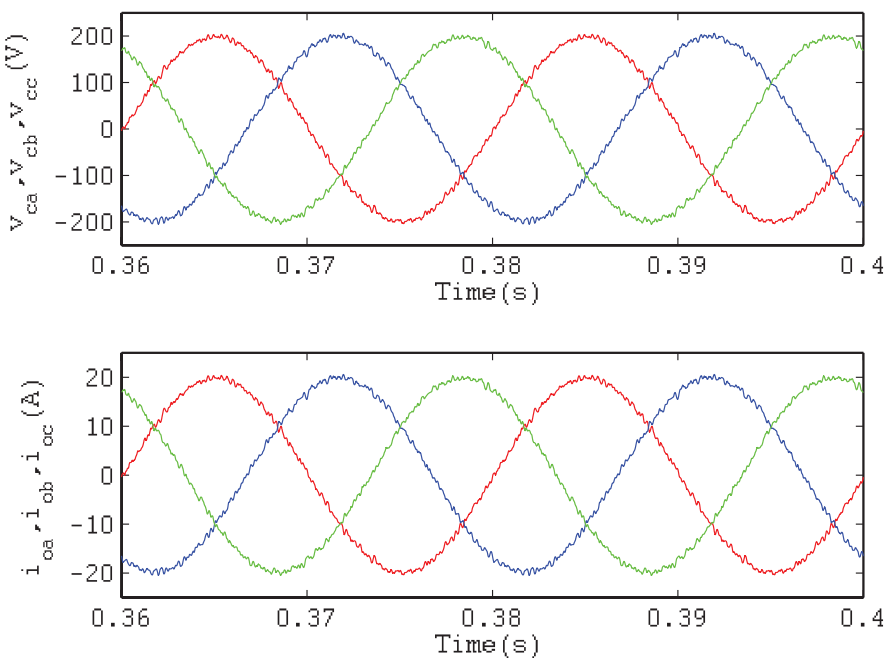

(b)

Fig. 6. Two steps prediction with resistive load. (a) Considering different vectors applied in $k$ and $k+1$. THD $=1.56 \%$. (b) Considering the same vector applied during $2 T_{s}$. THD $=1.54 \%$.



Fig. 7. Single-phase diode bridge rectifier used as part of the nonlinear load.

the model, which are not valid for such long prediction horizons.

In order to increase the number of prediction steps with further improvement of the system performance, more accurate models and considerations are required. More intelligent algorithms are also required in order to use a higher number of prediction steps without an increase of the computational effort. Possible solutions include the use of offline optimization. 



Fig. 8. One step prediction with nonlinear load. THD $=2.85 \%$.

\section{REFERENCES}

[1] O. Kukrer, "Deadbeat control of a three-phase inverter with an output LC filter," IEEE Trans. on Power Electronics, vol. 11, no. 1, pp. 16-23, January 1996.

[2] M. Kojima, K. Hirabayashi, Y. Kawabata, E. C. Ejiogu, and T. Kawabata, "Novel vector control system using deadbeat-controlled PWM inverter with output LC filter," IEEE Trans. on Industry Applications, vol. 40, no. 1, pp. 162-169, January/February 2004.

[3] P. Mattavelli, "An improved deadbeat control for UPS using disturbance observers," IEEE Trans. on Industrial Electronics, vol. 52, no. 1, pp. 206-212, February 2005.

[4] P. C. Loh, M. J. Newman, D. N. Zmood, and D. G. Holmes, "A comparative analisys of multiloop voltage regulation strategies for single and three-phase UPS systems," IEEE Trans. on Power Electronics, vol. 18, no. 5, pp. 1176-1185, September 2003.

[5] P. C. Loh and D. G. Holmes, "Analysis of multiloop strategies forLC/CL/LCL-filtered voltage-source and current-source inverters," IEEE Trans on Industry Applications, vol. 41, no. 2, pp. 644-654, March/April 2005.

[6] S. Buso, S. Fasolo, and P. Mattavelli, "Uninterruptible power supply multiloop control employing digital predictive voltage and current regulators," Trans. on Industry Applications, vol. 37, no. 6, pp. 1846-1854, November/December 2001.

[7] A. Kulka, T. Undeland, S. Vazquez, and L. G. Franquelo, "Stationary frame voltage harmonic controller for standalone power generation," in Power Electronics and Applications, 2007 European Conference on, Sep. 2007, pp. 1-10.

[8] M. N. Marwali and A. Keyhani, "Control of distributed generation systems-part i: Voltages and currents control," IEEE Transactions on Power Electronics, vol. 19, no. 6, pp. 1541-1550, Nov. 2004.

[9] G. Escobar, A. A. Valdes, J. Leyva-Ramos, and P. Mattavelli, "Repetitive-based controller for a UPS inverter to compensate unbalance and harmonic distortion," IEEE Trans. on Industrial Electronics, vol. 54 no. 1, pp. 504-510, February 2007.

[10] G. Escobar, P. Mattavelli, A. M. Stankovic, A. A. Valdez, and J. LeyvaRamos, "An adaptive control for UPS to compensate unbalance and harmonic distortion using a combined capacitor/load current sensing," IEEE Transactions on Industrial Electronics, vol. 54, no. 2, pp. 839-847, Apr. 2007.

[11] G. Willmann, D. F. Coutinho, L. F. A. Pereira, and F. B. Libano, "Multiple-loop H-infinity control design for uninterruptible power supplies," IEEE Trans. on Industrial Electronics, vol. 54, no. 3, pp. 15911602, June 2007.

[12] P. Cortes, M. P. Kazmierkowski, R. M. Kennel, D. E. Quevedo, and J. Rodriguez, "Predictive control in power electronics and drives," Industrial Electronics, IEEE Transactions on, vol. 55, no. 12, pp. 43124324, Dec. 2008.


(a)
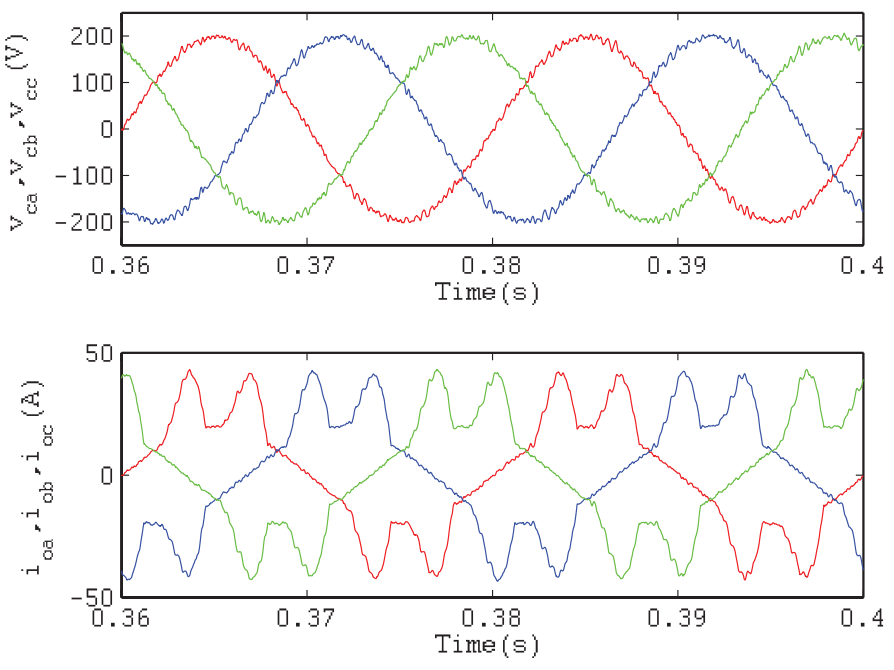

(b)

Fig. 9. Two steps prediction with nonlinear load. (a) Considering different vectors applied in $k$ and $k+1$. THD $=2.19 \%$. (b) Considering the same vector applied during $2 T_{s}$. THD $=2.17 \%$.

[13] R. Kennel and A. Linder, "Predictive control of inverter supplied electrical drives," Conf. Record of PESC'OO(Power Electronics Specialists Conference), vol. Galway, Ireland, June 2000, cD-ROM.

[14] A. Linder and R. Kennel, "Model predictive control for electrical drives," in Proc. of IEEE-PESC 05, Recife, Brazil, June 12-16 2005, pp. 1793 1799.

[15] E. F. Camacho and C. Bordons, Model Predictive Control. Springer, 2007.

[16] G. C. Goodwin, M. M. Serón, and J. D. Doná, Constrained Control and Estimation. Springer-Verlag, 2004.

[17] J. M. Maciejowski, Predictive Control woth Constraints. Prentice-Hall, 2001.

[18] V. Blasko and V. Kaura, "A new mathematical model and control of a three-phase AC-DC voltage source converter," IEEE Transactions on Power Electronics, vol. 12, no. 1, pp. 116-123, Jan. 1997.

[19] R. C. Portillo, M. M. Prats, J. I. Leon, J. A. Sanchez, J. M. Carrasco, E. Galvan, and L. G. Franquelo, "Modeling strategy for back-toback three-level converters applied to high-power wind turbines," IEEE Transactions on Industrial Electronics, vol. 53, no. 5, pp. 1483-1491, Oct. 2006.

[20] J. Kley, G. Papafotiou, K. Papadopoulos, P. Bohren, and M. Morari, "Performance evaluation of model predictive direct torque control," 
Power Electronics Specialists Conference, 2008. PESC 2008. IEEE, pp. 4737-4744, June 2008.

[21] M. Veenstra and A. Rufer, "Control of a hybrid asymmetric multilevel inverter for competitive medium-voltage industrial drives," Industry Applications, IEEE Transactions on, vol. 41, no. 2, pp. 655-664, MarchApril 2005.

[22] S. Muller, U. Ammann, and S. Rees, "New time-discrete modulation scheme for matrix converters," IEEE Trans. on Industrial Electronics, vol. 52, no. 6, pp. 1607-1615, December 2005.

[23] R. Vargas, J. Rodriguez, U. Ammann, and P. W. Wheeler, "Predictive current control of an induction machine fed by a matrix converter with reactive power control," Industrial Electronics, IEEE Transactions on, vol. 55, no. 12, pp. 4362-4371, Dec. 2008.

[24] J. Rodríguez, J. Pontt, C. Silva, P. Correa, P. Lezana, P. Cortés, and U. Ammann, "Predictive current control of a voltage source inverter," IEEE Trans. on Industrial Electronics, vol. 54, no. 1, pp. 495 - 503, February 2007.

[25] J. Rodríguez, J. Pontt, C. Silva, M. Salgado, S. Rees, U. Ammann, P. Lezana, R. Huerta, and P. Cortés, "Predictive control of a three-phase inverter," IEE Electronics Letters, vol. 40, no. 9, pp. 561-562, 29 April 2004.

[26] P. Cortes, J. Rodriguez, P. Antoniewicz, and M. Kazmierkowski, "Direct power control of an afe using predictive control," Power Electronics, IEEE Transactions on, vol. 23, no. 5, pp. 2516-2523, Sept. 2008.

[27] M. A. Perez, P. Cortes, and J. Rodriguez, "Predictive control algorithm technique for multilevel asymmetric cascaded h-bridge inverters," Industrial Electronics, IEEE Transactions on, vol. 55, no. 12, pp. 4354-4361, Dec. 2008.

[28] E. I. Silva, B. P. McGrath, D. E. Quevedo, and G. C. Goodwin, "Predictive control of a flying capacitor converter," in Proceedings of the American Control Conference, New York City, USA, Jul. 2007.

[29] P. Cortes, G. Ortiz, J. Yuz, J. Rodriguez, S. Vazquez, and L. Franquelo, "Model predictive control of an inverter with output $l c$ filter for ups applications," Industrial Electronics, IEEE Transactions on, vol. 56, no. 6, pp. 1875-1883, June 2009. 